\title{
VEGETARIANISM a healthy choice
}

Herath S

Vegetarianism has become a contentious and popular choice for many people all over the world. But parents may wonder whether their kids can safely follow a vegetarian diet and still get all necessary nutrients. Most dietary and medical experts agree that a well-planned vegetarian diet can actually be a very healthy way to eat. Vegetarianism is a general term used to describe people who exclude meat, poultry, fish, or other animalderived foods from their diets. Vegetarians exhibit a wide diversity of dietary practices. It's worth to be aware of various types of vegetarian diets as that all vegetarian diets are not alike. Major vegetarian categories include:

ovo-vegetarian: eats eggs; no meat

lacto-ovo vegetarian: eats dairy and egg products; no meat

lacto-vegetarian: eats dairy products; no eggs or meat vegan: eats only food from plant sources

Pesco: vegetarians who eat fish

There are many other different types of dietary practices such as, semi-vegetarians who have eliminated red meat, but may eat poultry or fish. One may practice vegetarianism for a variety of reasons. For example: religious, social or personnel. Younger vegetarians are usually part of a family that eats vegetarian meals for health, cultural, or other reasons. In most cases, you shouldn't be alarmed if your child chooses vegetarianism. Discuss what it means and how to implement it, ensuring your child makes healthy and nutritious food choices.

Should one consider following vegetarian diets? Is it scientific? Then what is the evidence? You may find a rational answer as you scrutinize this chart which compares Carnivores, Herbivores with Humans. This testifies that humans are born vegetarians.

\begin{tabular}{|c|c|c|c|}
\hline Comparison & Carnivores & Herbivores & Humans \\
\hline Vision in the night & Excellent & poor & poor \\
\hline Claw hand & present & absent & absent \\
\hline Dentition & $\begin{array}{l}\text { Sharp pointed front } \\
\text { teeth and molars with } \\
\text { cutting edges. }\end{array}$ & $\begin{array}{l}\text { Front teeth with cutting } \\
\text { edges and molars with } \\
\text { grinding surface. }\end{array}$ & $\begin{array}{l}\text { Front teeth with cutting edges } \\
\text { and molars with grinding } \\
\text { surface. }\end{array}$ \\
\hline Tongue & Surface is very rough & Surface is rough & Surface is rough \\
\hline Saliva & $\begin{array}{l}\text { Contains no digestive } \\
\text { enzymes }\end{array}$ & $\begin{array}{l}\text { Contains digestive } \\
\text { enzymes }\end{array}$ & Contains digestive enzymes \\
\hline Eating pattern & Smell and engulf & $\begin{array}{l}\text { Smell, taste and } \\
\text { swallow }\end{array}$ & Smell, taste and swallow \\
\hline $\mathrm{PH}$ in Stomach & Very acidic. $\mathrm{PH}<1$ & acidic & acidic \\
\hline Length of the Gut & $\begin{array}{l}\text { Not more than } 2 \text { to } \\
2.5 \text { times of the body } \\
\text { length }\end{array}$ & $\begin{array}{l}5 \text { to } 6 \text { times of the } \\
\text { body length }\end{array}$ & 5 to 6 times of the body length \\
\hline $\begin{array}{l}\text { Time to defecate } \\
\text { following a meal }\end{array}$ & Less than 8 hours & 24 to 36 hours & 24 to 36 hours \\
\hline
\end{tabular}

Consultant Respiratory Physician General Hospital Matara 
A well-planned vegetarian diet can meet day to day nutritional needs and has some health benefits. For example, a diet rich in fruits and veggies will be high in fiber and low in fat, factors known to improve cardiovascular health by reducing blood cholesterol and maintaining a healthy weight. However, young and adolescents on a vegetarian diet may need to be careful that they get an adequate amount of certain vitamins and minerals.

Here are nutrients that vegetarians should get and some of their best food sources:

vitamin B12: dairy products, and vitamin-fortified products, such as cereals, breads, and soy and rice drinks, and nutritional yeast

vitamin D: milk, vitamin D-fortified orange juice, and other vitamin $\mathrm{D}$-fortified products

calcium: dairy products, dark green leafy vegetables, broccoli, dried beans, and calcium-fortified products, including orange juice, soy and rice drinks, and cereals

protein: dairy products, tofu and other soy products, dried beans, and nuts

iron: dried beans, dried fruits, whole grains, leafy green vegetables, and iron-fortified cereals and bread

zinc: wheat germ, nuts, fortified cereal, dried beans, and pumpkin seeds

A vegetarian diet can be a healthy choice for all, as long as it's properly planned. The principles of planning a vegetarian diet are the same as planning any healthy diet - provide a variety of foods and include foods from all of the food groups. A balanced diet will provide the right combinations to meet nutritional needs. But be aware of potential nutrient deficiencies in your child's diet and figure out how you'll account for them. With a little exploration, you may find more vegetarian options than you realized. The Academy of Nutrition and Dietetics and Dietitians of Canada have stated that at all stages of life, a properly planned vegetarian diet is "healthful, nutritionally adequate, and provides health benefits in the prevention and treatment of certain diseases"(1).

Vegetarians tend to have lower body mass index,(2) lower levels of cholesterol, lower blood pressure, and less incidence of heart disease, hypertension, type 2 diabetes, renal disease, metabolic syndrome, dementias such as Alzheimer's disease, and obesity (3).

Furthermore certain cancers, osteoporosis, diverticular disease and gallstones are relatively low among vegetarians. Incidence of heart disease much lower as vegetarian's higher intake of fiber, antioxidants, vitamins, phytochemicals, and fats. Large-scale studies have shown that mortality from ischaemic heart disease was $30 \%$ lower among vegetarian men and $20 \%$ lower among vegetarian women than in non-vegetarians $(4,5)$

The more restricted the vegetarian diet the greater the challenge to achieve a nutritionally adequate diet. The goal for the vegetarian in diet planning is the same as the omnivore: consume a variety of foods to obtain all of the needed nutrients.

\section{Summary}

A vegetarian diet focuses on plants for food. These include fruits, vegetables, dried beans and peas, grains, seeds and nuts. There is no single type of vegetarian diet. Availability of various food ingredients are more or less the same in both plant origin and animal origin foods. People who follow vegetarian diets can get all the nutrients they need. However, they must be careful to eat a wide variety of foods to meet their nutritional needs (6),

\section{References;}

1. Appleby PN, Thorogood M, Mann JI, Key TJ (1998). "Low body mass index in non-meat eaters: the possible roles of animal fat, dietary fibre and alcohol". International journal of obesity and related metabolic disorders: journal of the International Association for the Study of Obesity 22 (5): 454460. doi:10.1038/sj.ijo.0800607. PMID 9622343

2. "Position of the American Dietetic Association: Vegetarian diets". July 2009. Retrieved November 18, 2012.

3. Key TJ, Fraser GE, Thorogood M, Appleby PN, Beral V, Reeves G, Burr ML, Chang-Claude J, Frentzel-Beyme R, Kuzma JW, Mann J, McPherson K (1999). "Mortality in vegetarians and nonvegetarians: detailed findings from a collaborative analysis of 5 prospective studies". The American Journal of Clinical Nutrition 70 (3 Suppl): 516S-524S.doi:10.1079/ phn19980006. PMID 10479225.

4. "Frequently Asked Questions - Definitions". International Vegetarian Union (IVU). Retrieved August 6, 2013.

5. Cross AJ, Leitzmann MF, Gail MH, Hollenbeck AR, Schatzkin A, Sinha R (2007). "A prospective study of red and processed meat intake in relation to cancer risk". PLoSMedicine 4(12): e325. doi:10.1371/journal. pmed.0040325. PMC 2121107.PMID 18076279.

6. "History of Vegetarianism - Extracts from some journals 1843-48". Ivu.org. Retrieved 2015-0331 